\title{
Food choice motives and intention to adopt personalised nutrition
}

\author{
A. Rankin ${ }^{1}$, L. J. Frewer ${ }^{2}$ and B. Stewart-Knox ${ }^{3}$ \\ ${ }^{1}$ Northern Ireland Centre for Food \& Health (NICHE), University of Ulster, Coleraine, BT52 1SA, ${ }^{2}$ Newcastle \\ University, Newcastle upon Tyne, NE1 7RU and ${ }^{3}$ University of Bradford, Bradford, BD7 1DP
}

Nutrigenomics is defined as the study of gene expression in relation to food and nutrition ${ }^{(1)}$. Personalised nutrition, however, encompasses dietary advice based on dietary, lifestyle, phenotypic and genotypic data ${ }^{(2)}$. Motives underlying the selection of food are hypothesised to serve as barriers to, and facilitators of, adoption of personalised nutrition ${ }^{(3)}$. The research presented here aimed to, therefore, explore food choice motives in relation to the intended uptake of personalised nutrition by the general public.

Findings from a previous qualitative study ${ }^{(4)}$ have been used to develop a questionnaire with which to probe consumer acceptance of personalised nutrition. Questionnaire items included the food choice questionnaire $(\mathrm{FCQ})^{(5)}$ and intention to adopt personalised nutrition in the future ${ }^{(6)}$. A representative sample from the UK $(n=1061)$ and Ireland $(n=1020)$, quota sampled based on age, sex, education level and region were surveyed on-line. Multi-group confirmatory factor analysis confirmed that the original 36-items from the 9-factor FCQ-model ${ }^{(5)}$ converged into the same 9-factors as the original scale. Food choice motives were then entered into multiple regression analysis as predictors of intention controlling for country, age, gender, and education level.

\begin{tabular}{|c|c|c|c|c|}
\hline Food choice motives & B & Std. Error & Beta & P-value \\
\hline Health & $0 \cdot 20$ & $0 \cdot 03$ & $0 \cdot 18$ & $<0 \cdot 001$ \\
\hline Mood & $0 \cdot 10$ & $0 \cdot 03$ & $0 \cdot 10$ & $<0 \cdot 001$ \\
\hline Convenience & $0 \cdot 06$ & $0 \cdot 02$ & 0.06 & $0 \cdot 01$ \\
\hline Sensory Appeal & $-0 \cdot 08$ & $0 \cdot 03$ & $-0 \cdot 07$ & $<0.001$ \\
\hline Natural Content & $0 \cdot 06$ & $0 \cdot 02$ & 0.07 & $0 \cdot 01$ \\
\hline Price & $-0 \cdot 05$ & $0 \cdot 02$ & $-0 \cdot 05$ & 0.02 \\
\hline Weight Control & $0 \cdot 16$ & $0 \cdot 02$ & $0 \cdot 19$ & $<0 \cdot 001$ \\
\hline Familiarity & $0 \cdot 02$ & $0 \cdot 02$ & $0 \cdot 02$ & $0 \cdot 48$ \\
\hline Ethical Concern & $0 \cdot 06$ & $0 \cdot 02$ & $0 \cdot 07$ & $<0.001$ \\
\hline
\end{tabular}

Significance at $P<0 \cdot 05$; Adjusted $R^{2}=0 \cdot 26$.

Results indicated that food choicemotivesexplained $21.9 \%$ of the variance in intention to adopt personalised nutrition, after country, age, gender, and education level had been controlled (R squared change $=0 \cdot 219$, F change $(9,2064)=68 \cdot 78, p<0 \cdot 001)$. The model shows that 8 of the 9 food choice motives significantly predicted intention to adopt personalised nutrition. Individuals motivated by health, mood, convenience, natural content, weight control, ethical concern, or scoring lower on sensory appeal and price may be more likely to adopt personalised nutrition. Personalised nutrition providers, therefore, may benefit from taking into consideration the underlying food choice determinants of potential consumers.

This work is supported by the EU funded 7th Framework Food 4 Me Project and the Department of Education and Learning (DEL).

1. Muller M, Kersten S (2003) Nat Rev Genet 4, 315-322.

2. Gibney G, Walsh M (2013) P Nutr Soc 72, 219-225.

3. Verplanken B, Wood W (2006) J Public Policy Mark 25, 90-103.

4. Stewart-Knox B, Kuznesof S, Robinson J, et al. (2013) Appetite 66, 67-74.

5. Steptoe A, Pollard TM, Wardle J, et al. (1995) Appetite 25, 267-284.

6. Ajzen I (1991) Organ Behav Hum Dec 50, 179-211. 